Research Article

\title{
Titanium dioxide nanoparticles decreases activity of rat brain when administered prenatally
}

\author{
Nikita Saraswat* ${ }^{1}$, Pranay Wal ${ }^{1}$, Ankita Wal ${ }^{1}$, Shikha Bajpai ${ }^{1}$, Rituparna Palit $^{2}$
}

\author{
${ }^{1}$ Department Pharmacy \\ Pranveer Singh Institute of \\ Technology, Kanpur, Uttar \\ Pradesh, India \\ ${ }^{2}$ Shri Ram Murti Smarak \\ College of Engineering and \\ Technology, Bareilly, Uttar \\ Pradesh, India
}

Received: 11 February 2016

Revised: 28 March 2016

Accepted: 04 April 2016

*Correspondence to:

Dr. Nikita Saraswat,

Email: nikita.saraswat07@

gmail.com

Copyright: (C) the author(s), publisher and licensee Medip Academy. This is an openaccess article distributed under the terms of the Creative Commons Attribution NonCommercial License, which permits unrestricted noncommercial use, distribution, and reproduction in any medium, provided the original work is properly cited.

\begin{abstract}
Background: Titanium dioxide nanoparticles are widely used in the sunscreens, toothpastes, and cosmetic products that the human use daily. Previous reports have proved that the impact of nanomaterials on brain activity is not negligible, especially for the people working in nanomaterials manufacturing factories. We are using titanium dioxide in our daily life in cosmetics, food industry and many other pharmaceutical products. So to keep a check on the threat what these chemicals may cause, we conducted a research to study effect of titanium dioxide nanoparticles on rat brain. This research gave us an insight of the possible threats it can cause to brain.

Methods: The effects of titanium dioxide nanoparticles on brain activity were reported. Our studies showed that titanium dioxide nanoparticles have a differential tendency towards neurons. To insight the possible effect on titanium dioxide nanoparticles on neurobehaviour we conducted a conditioned avoidance response study using shuttle box analysis. In the study we administered the drug titanium dioxide nanoparticles prenatally and observed its effects by neurobehaviour studies in progenies of wistar rat.

Results: In the results we observed that titanium dioxide nanoparticles have caused a decreased learning and memory behaviours as compared to control groups.

Conclusions: We studied the neurobehaviour of progenies, when the drug was administered to rat brain prenatally. The results showed that the titanium dioxide nanoparticles particles have decreased the brain activity of the rat brain by showing decreased brain activity in progenies also.
\end{abstract}

Keywords: Conditioned avoidance response, Brain damage, Neurotoxicity, Nanoparticles, Neurogenesis

\section{INTRODUCTION}

Titanium dioxide nanoparticles are widely used in all industries they can directly enter the hippocampal region of our brain by entering through the olfactory bulb. Direct exposure to nanoparticles, it has increased threat to human health as nanoparticles are being used currently in pharmaceutical products, cosmetics, food industries. ${ }^{1}$

Such wide use as well as potential entry through various ingestion, dermal and inhalational routes suggest that nano particles of titanium dioxide nanoparticles could pose a threat to humans, animals and other species. ${ }^{2}$ Various researches has shown that the inhaled and injected nanoparticles enter our body circulation and then migrates to organs and tissues causing severe damage., Recent research has pointed out that titanium dioxide nanoparticles is also toxic to ecological species and mammals. 5

\section{Titanium dioxide nanoparticles}

Nanotechnology is sciences that involves synthesis of particles in nano size range and has a growing application 
in medicine, biotechnology, food industries. ${ }^{6}$ The term nanoparticles (NPs) is used to define particles size less than $100 \mathrm{~nm}$ in diameter. NPs are generally termed as combustion-derived or manufactured NPs e.g., titanium dioxide nanoparticles. Titanium dioxide nanoparticles is also being used in a variety of consumer products (e.g. cosmetics, toothpastes, sunscreens, food products), in the environmental decontamination of air, soil, water and in paints and surface coatings. ${ }^{8,9,10}$ Various studies have reported that the nano-size particles, we inhale mostly enters the systemic circulation and then migrate to various organs and tissues where they accumulate and damage organ systems that are sensitive to oxidative stress (OS). ${ }^{11}$ As the studies show that as the size of nanoparticles decreases the toxicity ratio increases. ${ }^{12}$ The excess $\mathrm{O}_{2}$ arising from the oxidative stress can diffuse from the plasma membrane and damage the DNA, proteins, lipids of surrounding cells, especially neurons. ${ }^{13}$ As we know that titanium dioxide nanoparticles is chemically inert but titanium dioxide nanoparticles can cause negative health effects such as respiratory tract cancer in rats. ${ }^{14}$

\section{Oxidative stress}

Oxidative stress may induce DNA damage, lysosomal activation and autophagy, which may also represent a feedback mechanism to limit ROS-mediated cell activation by removing oxidatively damaged molecules and cell structure. ${ }^{15}$

\section{Neurogenesis}

Neurogenesis is the process by which neurons are generated. It is most active during the pre-natal development for growth of brain. In old times it was believed that the neurons do not replicate but now the researchers have proved that two areas of brain the dentate gyrus of hippocampal formation and sub ventricular zone and its projections to olfactory bulb, which can generate new neurons. ${ }^{16}$ In mammalian species, neurogenesis prevails lifetime in the sub ventricular zone of the lateral ventricle and sub granular zone of hippocampus dentate gyrus. ${ }^{17,18,19}$ The brain regions contain neural progenitor cells (NPC) which have capability to produce new neurons. ${ }^{21}$

\section{Neurotoxicity}

Neurotoxicology is the study of the harmful effects of biological, chemical and physical agents on the nervous system. $^{22}$ Many commonly used substances are neurotoxic, including ethanol, lead, mercury, lead and some pesticides. The symptoms appear immediately after exposure to the neurotoxins which include headache, obsessive behaviours, weakness, loss of memory, vision. $^{23}$ Titanium dioxide nanoparticles have three structural isoforms rutile, brookite and anatase. The anatase form of brookite was reported to be toxic that the rutile form. $^{24}$

\section{Applications of titanium dioxide nanoparticles}

\section{$U V$ protection and opacity}

One of the unique property of titanium dioxide nanoparticles is their increased ability to disperse light thus making it an essential ingredient of sunscreen and cosmetics thus protecting skin against UV light of sun. ${ }^{25,26,27}$ The large portion of nanotised titanium dioxide particles is majorly used in sunscreens and cosmetic products. Whereas titanium dioxide nanoparticles are good opacifiers and are used in coatings and paintings. ${ }^{28}$

\section{Antimicrobial applications}

The pure titanium dioxide nanoparticles or titanium dioxide nanoparticles doped with other materials like iron or silver exhibits antimicrobial properties. The excellent photo catalytic antimicrobial activity of titanium dioxide nanoparticles has increased their use in wall/glass coatings thus creating self-cleaning surfaces. ${ }^{29}$

\section{Healthcare applications}

The titanium dioxide nanoparticles are being used in healthcare industry. The titanium dioxide nanoparticles applied on bandages have shown increased blood clotting rates by forming increased blood clots. ${ }^{30} \mathrm{~A}$ platinum titanium dioxide nanoparticles nanocomposite has been shown to be effective in the treatment of cancer cells. ${ }^{31}$

\section{Summary of toxicology}

Nanoparticles can easily cross the blood brain barrier and enter the CNS of exposed of animals. ${ }^{32-34}$ Recently some studies have shown that inhaled nanoparticles easily reach brain and cause its neurodegenration. ${ }^{7}$ In the brain inflammation, apoptosis, oxidative stress is produced by nanoparticles thus releasing mediators from astrocyte and microglia. Neurodegeneration or neurotoxicity depends on the production of toxic or anti toxic mediators (antiinflammatory cytokines, neutrophils). ${ }^{7}$ The toxic effects of substances are easily measured in terms of acute, chronic, sub-acute, sub-chronic or chronic exposure conditions. The Acute toxicity information for titanium dioxide nanoparticles is currently very little. The smaller particles of titanium dioxide nanoparticles are more likely to cause cancer than the larger particles. The titanium dioxide nanoparticles dust is carcinogenic in nature. It is classified by the international agency for research on cancer (IARC) as a Group 2B carcinogen (titanium dioxide in 2006. These particles are mainly carcinogenic to humans. There is a little evidence that the rare disease of yellow nail syndrome may be caused by titanium, either by consuming various foods or implantations for medical reasons. The exposure to titanium dioxide nanoparticles can occur through manufacturing or by use. Titanium dioxide nanoparticles can be encountered through suspensions, emulsions, aerosols. The major routes of exposure to titanium dioxide nanoparticles is 
through dermal and inhalational exposure which have toxicological effects. The potential risk of exposure to these particles is at the workplace to human lungs. Such exposure can be greatly reduced by providing proper ventilation systems at workplace and thus reduces health risks. To the workers the exposure is possible through the handling and weighing. A study has shown that the occupational exposure at the workplaces in Korea at a manufacturing unit is high due to handling, bagging, mixing, over-cleaning, transferring thus high levels beyond the established limits of titanium dioxide nanoparticles was observed. ${ }^{35,36}$

\section{Experimental design}

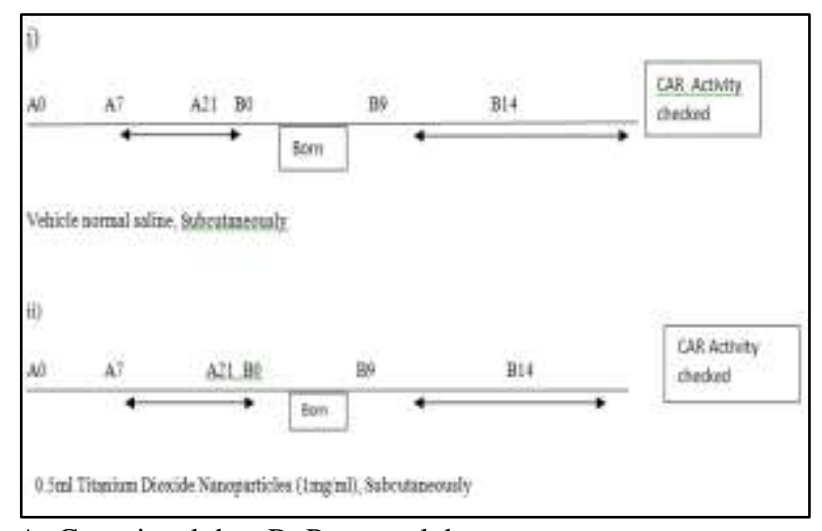

$\mathrm{A}=$ Gestational day, $\mathrm{B}=$ Post natal day

Figure 1: Shows the experimental designed for the research where $A$ represents the dosing performed on the pregnant wistar rat used as model for research and neurobehaviour is studied on pups born after 14 days of birth.

The objective of the study to investigate the effect of titanium dioxide nanoparticles on neurobehaviour of pups born (group $\mathrm{B}=$ postnatal) using $\mathrm{CAR}$ by injecting titanium dioxide nanoparticles prenatally (group $\mathrm{A}=$ prenatal).

The material used was titanium dioxide nanoparticles from Sigma Aldrich (USA) and the equipment used for the activity was shuttle box apparatus by Columbus instruments

\section{Animals}

Tweleve adult female albino rats of wistar strain of body weight 200-250 g were taken from Pranveer Singh Institute of Technology, Kanpur, India. Animal breeding colony approved by animal ethical committee and were used throughout experiment. These animals were kept in stainless steel and plastic polypropylene cages under the standard conditions with 12 hours of light and dark cycle and a temperature of $25+2^{\circ} \mathrm{C}$. The animals were at $a d$ libitum access to drinking water and pellet diet. The animal care ethical committee approved all experimental protocols applied to the animals.

\section{Animal dosing}

Table 1: Table shows the dosing schedule performed on wistar rat where control column shows the drug administered as well as the dosing duration and treated group column shows the drug administered and duration of dosing.

\begin{tabular}{|c|c|c|}
\hline Groups & Treatment & $\begin{array}{l}\text { Duration of } \\
\text { Treatment }\end{array}$ \\
\hline Control & $\begin{array}{l}\text { Normal saline } \\
\text { subcutanoeusly }\end{array}$ & $\begin{array}{l}\text { Daily for } 15 \\
\text { consecutive days } \\
\text { from A7-A21 } \\
\text { days. }\end{array}$ \\
\hline Treated & $\begin{array}{l}0.4 \mathrm{ml} \text { titanium dioxide } \\
\text { nanoparticles }(1 \mathrm{mg} / \mathrm{ml}) \\
\text { body weight } \\
\text { subcutaneously }\end{array}$ & $\begin{array}{l}\text { Daily for the } \\
\text { same duration } \\
\text { from A7-A21 } \\
\text { days. }\end{array}$ \\
\hline
\end{tabular}

$\mathrm{A}=$ Gestational day, $\mathrm{B}=$ Post natal day

\section{METHODS}

In order to understand the effect of titanium dioxide nanoparticles on neurobehavioral parameters such as shuttle box were carried out in pups born after the dose was administered to the pregnant wistar rats. Conditioned avoidance response (CAR) the brain capacity of animals (post natal) was measured by a two way apparatus known as shuttle box apparatus (Columbus instruments). The method published is a psychological test for learning and memory in rats. ${ }^{37}$ The suttle box consists of two chambers partitioned by acrylic sheets and connected through a $10 \mathrm{~cm} \times 6 \mathrm{~cm}$ passage in it. At one time the shock could be delivered to one chamber through grid floor (intensity according to body weight), thus other chamber remains as shock proof. In each activity the buzzer was blown which served as a source of conditioned stimulus then followed by shock $(0.5 \mathrm{~mA}$ up to $10 \mathrm{~s}$ ) that served as a unconditioned stimulus. The activity of 8 rats from each group was assessed. The rats of both groups control and treated were kept one by one in one chamber 15 trials/day, repeated up to few days. The activity was continued until $90 \%$ CAR in control group was obtained so as to draw a comparison between control and treated groups. When the retention and learning ability was recorded up to $90 \%$ CAR then a comparison was drawn between the treated and control groups for the same day. The percentage of CAR was considered as a measure for the brain ability between the treated and control groups for interpretation of learning and memory. For checking the memory from learning process the animals were kept for 7 days and the CAR measured in both groups, then $\%$ memory in treated groups was calculated and compared to control.

\section{RESULTS}

Conditioned avoidance response (CAR): titanium dioxide nanoparticles caused a major decrease in the learning and memory in the animals born after dosing pregnant wistar 
rats as compared to the pups of control group of rats. The learning and memory ability of titanium dioxide nanoparticles treated rats was assessed using shuttle box apparatus by conditioned avoidance response method. It is a psycho pharmacological test for memory learning in rats. The treated and control group animals were trained and tested for a duration of 4 days in the shuttle box followed by shock and buzzer. Then the learning of animals moving to the other non-shock chamber was recorded. Similarly the results of memory assessment were recorded after seven days after training. Thus the results for learning and memory were summarised as percentage learning and memory which suggested a decrease in learning and memory in titanium dioxide nanoparticles treated rats as compared to the control group.

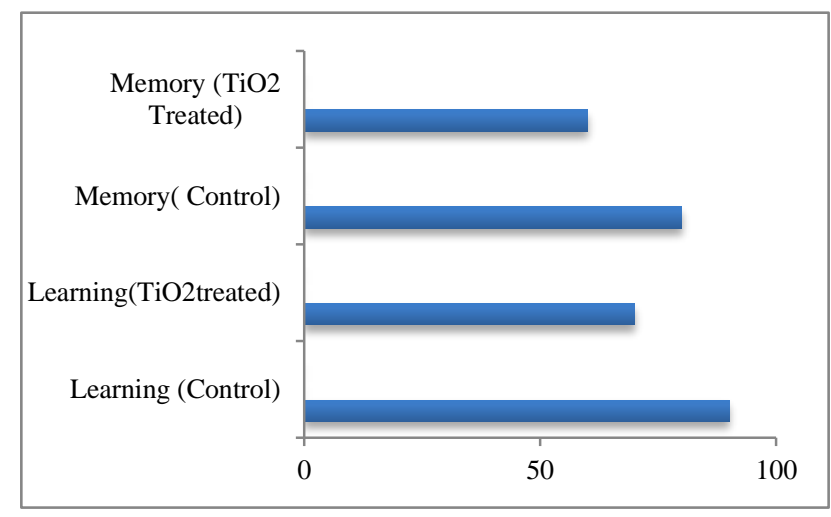

Percentage $(\%)$ conditioned avoidance response.

Figure 2: Graph shows the percentage decrease in memory and learning of treated animals as compared to control group when CAR performed postnatlly on pups.

\section{DISCUSSION}

In previous studies it has been clearly proved that titanium dioxide nanoparticles cause toxicity in other forms also. As one study conducted by Ran Liu et al proved that $\mathrm{TiO}_{2}$ nanoparticles causes pulmonary toxicity where the particles size and dose exposure played an important role. $^{38}$

Some researchers have also stated the need to carry out the work for checking the toxicities caused by titanium dioxide nanoparticles affecting postnatal and prenatal developments. They clearly state the need for studying the biological status such as pregnancy and placental barriers which we performed through our research work. ${ }^{39}$

When the results were studied, we concluded that after administering titanium dioxide nanoparticles the post natal neurobehavioral activities of the mice decreased as compared to the normal treated mice which were administered saline. Hence we can conclude that the titanium dioxide nanoparticle which is being used in the daily needs is posing a threat to the neural health and decreasing the brain activities.

\section{CONCLUSION}

The research performed clearly showed that when the drug titatnium dioxide nanoparticles were given prenatally then the pups showed a decrease in neurobehavioural activity as compared to the control group. The neurobehaviour of wistar rats was affected when titatnium dioxide nanoparticles were given subcutaneously

\section{AKNOWLEDGEMENT}

The author would like to thank the depertment of pharmacy for the support and guidance for the research, Pranveer Singh Institute of Technology, Kanpur, U.P, India.

Funding: Pranveer Singh Institute of Technology, Kanpur, Uttar Pradesh, India

Conflict of interest: None declared

Ethical approval: The study was approved by the Institutional Ethics Committee

\section{REFERENCES}

1. Yuguan Z, Sheng L, Zhao X, Hong J. Titanium dioxide nanoparticles nanoparticles induced hippocampal neuroinflammation in mice. PLoS One. 2014;9(3):e92230.

2. Nanotoxicology: Toxicological and Biological activities of nanomaterials, The Chinese academy of sciences. Available at http://www.eolss.net/samplechapters/c05/e6-152-35-00.pdf. Accessed 12 December 2015.

3. Kreyling WG, Semmler M, Erbe F, Mayer P, Takenaka S, Schulz H, et al, Translocation of ultrafine insoluble iridium particles from lung epithelium to extrapulmonary organs is size dependent but very low. J Toxicol Environ Health A. 2002;65(20):1513-30.

4. Takenaka S, Karg E, Roth C, Schulz H, Ziesenis A, Heinzmann U, et al. Pulmonary and systemic distribution of inhaled ultrafine silver particles in rats. Environ Health Perspect. 2001;109:547-51.

5. Adams LK, Lyon DY, Mcintosh A, Alvarez PJ. Comparative toxicity of nano-scale Titanium dioxide nanoparticles, $\mathrm{SiO}_{2}$ and $\mathrm{ZnO}$ water suspensions. Water Sci Technol. 2006;54:327-34.

6. Zhang L, Bai R, Li B, Ge C, Du J, Liu Y,et al Rutile titanium dioxide nanoparticles particles exert size and surface coating dependent retention and lesions on the murine brain. Toxicol Lett. 2011;207(1):73-81.

7. Shwe TTW, Fujimaki H. Nanoparticles and Neurotoxicity. Int J Mol Sci. 2011;12(9):6267-80.

8. Kaida T, Kobayashi K, Adachi M, Suzuki F. Optical characteristics of titanium oxide interference film and the film laminated with oxides and their applications for cosmetics. Cosmet Sci. 2004;55:219-20. 
9. Choi H, Stathatos E, Dionysiou DD. Sol-gel preparation of meso porous photocatalytic titanium dioxide nanoparticles films and titanium dioxide nanoparticles $/ \mathrm{Al}_{2} \mathrm{O}_{3}$ composite membranes for environmental applications. Appl Catal BEnviron.2006;63:60-7

10. Fisher J, Egerton T. Titanium compounds, inorganic: Kirk-Othmer Encyclopedia of Chemical Technology. New York: John Wiley and Sons; 2001.

11. Kreyling WG, Semmler M, Erbe F, Mayer P, Takenaka S, Schulz $\mathrm{H}$, et al. Translocation of ultrafine insoluble iridium particles from lung epithelium to extrapulmonary organs is size dependent but very low. J Toxicol Environ Health A. 2002;65:1513-30.

12. Sager TM, Kommineni C, Castranova V. Pulmonary response to intratracheal instillation of ultrafine versus fine titanium dioxide: role of particle surface area. Particle and Fibre Toxicology. 2008;5:17.

13. Long TC, Saleh N, Tilton RD, Lowry VG, Veronesi B. Titanium dioxide (P25) produces reactive oxygen species in immortalized brain microglia (BV2): implications for nanoparticle neurotoxicity. Environ Sci Technol. 2006;40(14):4346-52.

14. Trouiller B, Reliene R, Westbrook A, Solaimani P, Robert H. Schiest L, Titanium dioxide nanoparticles induce DNA damage and genetic instability in-vivo in mice. American Association for cancer research. Cancer Res. 2009;69:22.

15. Chen Y, Azad MB, Gibson SB. Super oxide is the major reactive oxygen species regulating autophagy.Cell Death Diff. 2009;16:1040-52.

16. Gage FH. Neurogenesis in the Adult Brain, California. The Journal of Neuroscience. 2002;22(3):612-3.

17. Doetsch F, Caille I, Lim DA, Garcia-Verdugo JM, Alvarez BA. Subventricular zone astrocytes are neural stem cells in the adult mammalian brain. Cell. 1999;97,703-16.

18. Eriksson PS, Perfilieva E, Eriksson TB, Alborn AM, Nordborg C, Daniel A, et al. Neurogenesis in the adult human hippocampus. Nature Medicine. 1998;4:1313-7.

19. Johansson C, Deveney AM, Reif D, Jackson DM. The neuronal selective nitric oxide inhibitor AR-R 17477 , blocks some effects of phencyclidine, while having no observable behavioural effects when given alone. Pharmacol Toxicol. 1999;84:226-33.

20. Cameron HA, Mckay RD. Adult neurogenesis produces a large pool of new granule cells in the dentate gyrus. J Comp Neurol. 2001;435(4):406-17.

21. Praag HV, Alejandro F, Schinder, Brian R, Christie, Toni N, et al. Functional neurogenesis in the adult hippocampus.Nature. 2002;415:1030-4.

22. Harry GJ, Billingsley M, Bruinink A, Campbell IL, Classen W, Dorman DC, et al. In-vitro techniques for the assessment of neurotoxicity. Environ Health Perspect. 1998;106(1):131-58.

23. Chen Y, Garcia GE, Huang W, Shlomi C. The involvement of secondary neuronal damage in the development of neuropsychiatric disorders following brain insults. Front Neurol. 2014;5:22-4.

24. Sayes CM, Wahi R, Kurian PA, Liu Y, West JL, Ausman KD, et al. Correlating nanoscale titania structure with toxicity: a cytotoxicity and inflammatory response study with human dermal fibroblasts and human lung epithelial cells. Toxicol Sci. 2006;92:174-85.

25. Nanomaterial Case Studies: Nanoscale Titanium Dioxide in Water Treatment and in Topical Sunscreen. Available at https://cfpub.epa.gov /ncea/risk/ recordisplay.cfm?deid. Accessed 18 December 2015.

26. Lorenz C, Tiede K, Tear S, Boxall A, Goetz N, Hungerbuhler $\mathrm{K}$. Imaging and characterization of engineered nanoparticles in sunscreens by electron microscopy, under wet and dry conditions. International Journal of Occupational Environmental Health. 2010;16(4):406-28.

27. Kowalkowskia T, Buszewskia B, Cantadob C, Dondib F. Field-flow fractionation: Theory, techniques, applications and the challenges. Critical Reviews in Analytical Chemistry. 2006;36(2):129-35.

28. Adams LK, Lyon DY, Mcintosh A, Alvarez PJ. Comparative toxicity of nano-scale titanium dioxide nanoparticles, $\mathrm{SiO} 2$ and $\mathrm{ZnO}$ water suspensions. Water Sci Technol. 2006;54:327-34.

29. Luan J, Wang S, Hu Z, Zhang L. Synthesis techniques, properties and applications of polymer nanocomposites. Curr Org Synth. 2012;9:114-36.

30. Roy SC, Paulose M, Grimes CA. The effect of titanium dioxide nanoparticles nanotubes in the enhancement of blood clotting for the control of hemorrhage. Biomaterials. 2007;28(31):4667-72.

31. Liu L, Miao P, Xu Y, Tian Z, Zou Z, Li G. Study of $\mathrm{Pt} /$ Titanium dioxide nanoparticles nanocomposite for cancer-cell treatment. J Photochem Photobiol B. 2010;98(3):207-10.

32. Lockman PR, Koziara JM, Mumper RJ, Allen DD. Nanoparticle surface charges alter blood-brain barrier integrity and permeability. Journal of Drug Targeting. 2004;12:635-41.

33. Kreyling WG, Semmler M, Erbe F, Mayer P, Takenaka S, Schulz H, Oberdorster G, Ziesenis A. Translocation of ultrafine insoluble iridium particles from lung epithelium to extrapulmonary organs is size dependent but very low. Journal of Toxicology and Environmental Health Part A.2002;65:1513-30.

34. Oberdorster G, Sharp Z, Atudorei V, Elder A, Gelein R, Kreyling W, Cox C. Translocation of inhaled ultrafine particles to the brain. Inhalation Toxicology. 2004;16:437-45.

35. Curwin B, Bertke $S$, Exposure characterization of metal oxide nanoparticles in the workplace. J Occup Environ Hyg. 2011;8(10):580-7.

36. Lee YS, Kim DW, Lee YH, Oh JH, Yoon S, Choi MS, et al. Silver nanoparticles induce apoptosis and G2/Marrest via PKCf-dependent signaling in A549 lung cells. Arch Toxicol. 2011;85:1529-40. 
37. Moreira KM, Hipolide DC, Nobrega JN, Bueno OF, Tufik S, Oliveira MG. Deficits in avoidance responding after paradoxical sleep deprivation are not associated with altered $[3 \mathrm{H}]$ pirenzepine binding to M1 muscarinic receptors in rat brain. Brain Res. 2002;977:31-7.

38. Liu R, Yin L, Pu Y, Liang G, Zhang J, Su J, et al. Pulmonary toxicity induced by three forms of titanium dioxide nanoparticles via intra- tracheal instillation in rats, Progress in Natural Science. 2009;19:573-79.

39. Rollerova E, Tulinska J, Liskova A, Kuricova M, Kovriznych J, Mlynarcikova A, Kiss A, Scsukova S. Titanium dioxide nanoparticles: some aspects of toxicity/focus on the development, Endocrine Regulations. 2015;49:97-112.

Cite this article as: Saraswat N, Wal P, Wal A, Bajpai S, Palit R. Titanium dioxide nanoparticles decreases activity of rat brain when administered prenatally. Int J Basic Clin Pharmacol 2016;5:733-8. 